\title{
Interpretações cuyanas sobre a geografia no Brasil
}

\author{
( Paulo Roberto de Albuquerque Bomfim \\ Departamento de Humanidades, Instituto Federal de Educação, Ciência e Tecnologia de \\ São Paulo (IFSP), São Paulo, Brasil.
}

Recibido: 1 de febrero de 2020. Aceptado: 23 de marzo de 2020.

\begin{abstract}
Resumo
O objetivo principal deste artigo é investigar, a partir da leitura do Boletín de Estudios Geográficos publicado pela Universidad Nacional de Cuyo (Mendoza), como o Brasil e a geografia produzida no Brasil despertaram interesse entre geógrafos argentinos nas décadas de 1950 e 1960. A Universidad de Cuyo foi o epicentro das relações acadêmicas exteriores na Argentina, lugar que será ocupado pela Universidad de Buenos Aires nos anos de 1970. Identificamos nos números do Boletín comentários, notas e artigos que evidenciam a circulação de geógrafos brasileiros e argentinos entre Mendoza e instituições/locais brasileiros, como Rio de Janeiro, Instituto Brasileiro de Geografia e Estatística e Associação dos Geógrafos Brasileiros. Os geógrafos argentinos desejavam um aggiornamento de suas linhas de pesquisa, numa perspectiva de inserção no planejamento como instrumento de superação do subdesenvolvimento das economias latino-americanas. Os textos do Boletín demostram também forte influência da geografia francesa. Esse contato com as produções brasileiras e francesas assinala caminhos teóricos da geografia na Argentina permeados por rubricas como geografia aplicada, geografia tropical etc., que marcam logros e impasses nas reflexões geográficas locais, corroborando um rico intercâmbio geográfico transnacional, muitas vezes pleno de contradições teóricas e político-ideológicas.
\end{abstract}

PALAVRAS-CHAVE: HISTÓRIA DA GEOGRAFIA. BOLETÍN DE ESTUDIOS GEOGRÁFICOS. REDES E TRAJETÓRIAS GEOGRÁFICAS. GEOGRAFIA NA ARGENTINA. BRASIL E FRANÇA. PERIÓDICOS GEOGRÁFICOS.

\section{Interpretations from Cuyo about geography in Brazil}

\begin{abstract}
The main objective of this article is to investigate, from the reading of the Boletin de Estudios Geográficos, published by the Universidad Nacional de Cuyo (Mendoza), how Brazil and the geography produced in Brazil stimulated interest among Argentinian geographers in the 1950 os and 1960s. The University of Cuyo was the epicenter of foreign academic relations in Argentina, a place that will be occupied by the University of
\end{abstract}


Buenos Aires in the 1970s. In the Boletín numbers we identified comments, notes and articles that show the movement of Brazilian and Argentinian geographers between Mendoza and institutions/places in Brazil, such as Rio de Janeiro, Instituto Brasileiro de Geografia e Estatística and Associação dos Geógrafos Brasileiros. Argentinian geographers wanted an increase of their lines of research from the perspective of insertion in planning as an instrument to overcome the underdevelopment of Latin American economies. The texts of Boletín also demonstrate strong influence of the French geography. This contact with Brazilian and French productions marks theoretical paths of geography in Argentina, permeated by rubrics such as applied geography, tropical geography, etc., which point achievements and impasses in local geographical reflections, corroborating a rich transnational geographic exchange, often full of theoretical and political-ideological contradictions.

KEYWORDS: HISTORY OF GEOGRAPHY. BOLETÍN DE ESTUDIOS GEOGRÁFICOS. GEOGRAPHICAL NETWORKS AND PATHWAYS. GEOGRAPHY IN ARGENTINA. BRAZIL AND FRANCE. GEOGRAPHICAL JOURNALS.

PALABRAS CLAVE: HISTORIA DE LA GEOGRAFÍA. BOLETÍN DE ESTUDIOS GEOGRÁFICOS. REDES Y TRAYECTORIAS GEOGRÁFICAS. GEOGRAFÍA EN LA ARGENTINA. BRASIL Y FRANCIA. PERIÓDICOS GEGRÁFICOS.

\section{Introdução}

Periódicos acadêmicos testemunham certamente as intenções de uma ciência ou de uma comunidade científica em fomentar seu campo científico, conforme essas publicações se tornam parte das redes institucionais que as legitimam culturalmente sob o pano de fundo das estruturas sociais, econômicas e políticas de contextos específicos (Bourdieu, 1997; Lima, 2010). Assim, a investigação crítica de periódicos constitui uma interessante fonte para compreender a capilaridade de uma ciência, as influências recebidas e exercidas por determinado grupo em torno de uma revista (mormente atrelada a universidades ou sociedades), bem como posicionamentos políticos e ideológicos, nem sempre, claro, absolutamente explícitos, o que requer um fundamental cotejamento entre os escritos e os contextos acadêmicos e-de modo geral- históricos; nacionais e internacionais. No caso, pretende-se investigar de que maneira a geografia produzida no Brasil despertou interesses (variados) sobre uma parte da produção geográfica argentina entre meados dos anos de 1950-1960.

Muito sinteticamente, de acordo com conhecidas acepções de Berdoulay (2008), a leitura a que nos propomos considera o estudo da história do pensamento geográfico no marco da história social das ideias. Tal acepção nos leva a buscar compreender, no contexto dos processos de institucionalização da geografia na Argentina e no Brasil, como se deu a formação de redes transnacionais de pesquisadores, assim como indagar acerca dos compromissos políticos e da circulação, apropriação e reelaboração das ideias. Vale lembrar que tais processos não são alheios à procura, por parte dos geógrafos, de estratégias de adquirir maior “capital simbólico", traduzido em luta por reconhecimento e prestígio acadêmico (Bourdieu, 1989; 1997).

Compreendemos também os processos de alteridade na circulação de ideias no marco da geografia como ciência em situação colonial. Ou seja: devemos ir além da simples desconstrução do olhar imperial nas geografias latino-americanas. Seguindo algumas reflexões de Said, Zusman (1999:174) destaca a importância da plasticidade na 
circulação transnacional de ideias, argumentando que as variações sofridas por tal trânsito (num evidente câmbio de contextos históricos e geográficos) acarretam pensar em como as diferentes teorias, ao se moverem, sujeitam-se às condições de aceitação/ resistência, bem como a processos de reelaboração total ou parcial. Para Marie Louise Pratt (1999) e Singaravélou (2008:55), a situação colonial significaria a busca da lógica própria das geografias da alteridade, cruzando aproximações internalistas e externalistas, convidando-nos a pensar até que ponto essas geografia -geografia dos exploradores, geografia colonial, geografia tropical etc- teriam/seriam rupturas, linhas condutoras, reelaborações em contextos como os de o Brasil e Argentina.

\section{O Boletín de Estudios Geográficos e a construção da geografia em Mendoza}

Localizada em Mendoza, a Universidad Nacional de Cuyo foi uma das instituições acadêmicas argentinas mais relevantes no período apontado no que se refere à primazia de publicações e de intercâmbios, reelaborações e circulações de ideias (certamente de mão-dupla) entre França e Brasil/Argentina.

O Boletín de Estudios Geográficos (BEG) começa a ser publicado em 1948, ainda sob os auspícios da Sección de Estudios Geográficos da Universidad de Cuyo, quando a geografia então era uma seção do Instituto de Historia y Disciplinas Auxiliares, dirigido por Martín Pérez. Por muito tempo, o Boletín foi uma das principais revistas acadêmicas de geografia na Argentina, circulando entre 1948 e 1972, reaparecendo a partir de 1981 e até os dias de hoje.

Interessa-nos destacar o ano de 1956 -quando, num contexto antiperonista, a geografia se torna uma carreira desvinculada da história- e 1972, momento em que o boletim deixa de circular, como hipótese, devido à primavera peronista, contexto em que conheceu efêmera força a Nueva Geografía, a geografia crítica marxista, questionadora de muitas das posturas acadêmicas tradicionais (Bietti, 2019), deixando no ostracismo muitos professores antigos. Muitos geógrafos mendoncinos e portenhos eram vinculados à GAEA (Sociedad Geográfica Argentina), órgão ligado a uma visão conservadora da geografia, onde circulavam antiperonistas e personagens como Federico Daus (1961), Osvaldo Inchauspe; Mariano Zamorano, Ricardo Capitanelli, Raúl Rey Balmaceda (professor na Universidad de Buenos Aires); todos defensores nos Anais da GAEA da geografia aplicada.

Vanesa Iut (2014) destaca que o Boletín foi a primeira revista acadêmica argentina a conter editoriais, artigos, traduções, resenhas, comentários; semelhante à estrutura -em menor proporção- da Revista Brasileira de Geografia (uma hipótese nossa atestando uma inspiração), sendo possivelmente outro modelo para o BEG os Cahiers d'OutreMer, publicados em Bordeaux a partir (também) de 1948. Tal pequena hipótese se consubstancia no fato de que muitos geógrafos argentinos fizeram especializações em Bordeaux, sob orientação de Louis Papy, Henri Enjalbert, dentre outros, principalmente a partir de meados dos anos de 1950.

Pois bem: a leitura dos artigos do periódico revela a marca da influência francesa na institucionalização da geografia na Argentina e no Brasil (Cicalese, 2014; Machado, 
2002; Massi, 1991; Silva, 2012; Zusman, 1997, 1999), assim como as tramas diplomáticas que permitiram a circulação de geógrafos entre Mendoza e (sobretudo) Bordeaux; além de Toulouse, Paris etc. (Cicalese, 2014; Pelosi, 1999). Ansiando por um aspecto pragmático da geografia para a superação do subdesenvolvimento por uma via intervencionista do Estado, bem ao gosto das políticas diplomático-acadêmicas francesas latino-americanistas (nas quais Pierre Monbeig foi figura central no campo das humanidades), não escapava àqueles que escreveram no BEG (Pierre Monbeig, Pierre George e nomes menos conhecidos no Brasil como Mariano Zamorano, Ricardo Capitanelli, Paul-Yves Denis e Romain Gaignard) um fecundo interesse pelo Brasil.

Em suma, a geografia argentina procurava compreender e acompanhar o que se passava na economia, na política e na sociedade brasileiras, buscando também uma inserção em espaços como os da Associação dos Geógrafos Brasileiros e em algumas universidades do Brasil. "Aberta ao exterior" (Romano, 2011), a geografia em Mendoza fomentou a presença de geógrafos franceses e brasileiros (Aziz Ab’Saber, Ney Strauch etc.) como conferencistas em Mendoza e/ou colaboradores no BEG. Essa percepção das geografias entre dois continentes é marcada em termos teóricos pelas nomenclaturas acima indicadas (geografia tropical, geografia aplicada etc.).

Para avançar na investigação da geografia em Cuyo e sua abertura ao exterior faz-se mister desvelar brevemente o papel cultural e acadêmico francês na Argentina.

\section{Os geógrafos-diplomatas ou as afinidades eletivas}

A geografia francesa conseguira se firmar na primeira metade do século XX como ciência de grande capilaridade no meio universitário, dotada de um arcabouço teórico relativamente coeso, embora cedo se detectassem estagnações no modelo das "monografias regionais” (Robic, 2005). Ao mesmo tempo, o estilo diplomático francês -não só governamental, mas também empresarial- marcava posição deste lado do Atlântico desde os primeiros anos do século passado.

Pelo início do século XX, a presença francesa no Cone Sul evidenciou uma íntima relação entre anseios diplomáticos e ciência. Essas costuras estiveram imbricadas na institucionalização da geografia -e dos cursos de geografia/história- no Brasil e na Argentina. Nesse contexto, são engendradas tanto a "missão" universitária no Brasil (São Paulo e Rio de Janeiro, basicamente) (Massi, 1991:198-199; Silva, 2012; Zusman, 1999) como as iniciativas culturais francesas na Argentina, a exemplo do Instituto da Universidade de Paris em Buenos Aires (Pelosi, 1999).

Duas modalidades de cursos de geografia conviveram -e ainda convivem - na Argentina: o professorado e os cursos superiores, semelhante à separação que se convencionou no Brasil entre licenciaturas e bacharelados. Em ambos os países, os cursos superiores de geografia estavam vinculados aos de história e a década de 1950 testemunha a separação/criação de grande parte deles. Assim, a despeito de departamentos e cátedras de geografia existentes desde o começo do século XX (vinculados à história ou aos professorados), os cursos de geografia surgem, por exemplo, em Buenos Aires (1953), La Plata (1948), Tucumán (1948), Bahía Blanca (1957) e Resistencia (1958), atestando como os "saberes geográficos" tiveram grande monta em cursos de formação de professores (Chiozza, 1987:13-14). 
As décadas de 1950-1960 assinalam igualmente a tensão entre as perspectivas regionais descritivas e aquelas mais voltadas à planificação. Exemplifica essa crise o posicionamento segundo o qual a aplicação da geografia deveria ser intrínseca ao caráter sintético da disciplina -que estaria presa à descrição e a um papel ornamental-. Ao contrário, à geografia urgia se tornar uma ciência ligada ao planejamento territorial e aos homens de ação (Juillard, 1958; Tricart, 1958). No mesmo tom, a geografia deveria abandonar sua ineficaz função de "disciplina de cultura" e se voltar à formação de uma "elite de técnicos” (Phlipponneau, 1960:15).

Enfatiza o período por nós abarcado também novos objetivos franceses tanto no Brasil como na Argentina. Como assinala J. Borzacchiello da Silva (2012), a partir do XVIII Congresso Internacional de Geografia, ocorrido no Rio de Janeiro em agosto de 1956, cuja audiência contou com vários geógrafos estado-unidenses e soviéticos, reativam-se as missões de geógrafos franceses. Bernard Kayser, Michel Rochefort (ambos sob os auspícios de Milton Santos), dentre outros, circulam na virada para os anos de 1960 pela Universidade da Bahia e pelo Instituto Brasileiro de Geografia e Estatística (IBGE) (Silva, 2012).

Na Argentina, sua neutralidade durante a Guerra custara-lhe uma posição secundada nos anos de ouro do capitalismo. Como no Brasil, a planificação de via keynesiana entrara no repertório, sofrendo, porém, diversos revezes num ambiente político muito convulsionado, desde Perón até a Revolução Argentina e o período final, anterior à ditadura militar instaurada em 1976.

É nesse contexto que a diplomacia acadêmica francesa investiu em fortes intercâmbios latino-americanos. O Ministério das Relações Exteriores da França, por meio de sua Secretaria de Assuntos Culturais, teve papel direto na indicação de nomes como os de Yves Leloup, como professor de geografia no Brasil, Olivier Dolfuss no Peru, Jean Bordes no Chile, Claude Bataillon no México e Romain Gaignard na Argentina (Huerta, 2003:18).

Praticamente desconhecido no Brasil, Gaignard intentava estudar, à sombra de Monbeig, as frentes pioneiras e a longa duração no processo de formação territorial argentina. Chega em 1960 na Universidad de Cuyo, onde se encarrega da disciplina Geografia do Hemisfério Oriental I e II. A exemplo de Louis Papy e Henri Enjalbert, estruturou laços importantíssimos não somente entre Bordeaux e Mendoza: residindo na Argentina por anos, Gaignard fomentou/impulsionou as geografias em La Plata, Bahía Blanca, Resistencia etc. A presença de Gaignard nos revela como se explicitariam outros interesses franceses -ainda para ficarmos num campo acadêmico, sem adentrarmos em aspectos econômicos-. Os arranjos diplomáticos concebidos pelo governo francês davam, por meio do CNRS (Centre National de la Recherche Scientifique), grande peso ao ensino superior em humanidades, fomentando intercâmbios fecundos, muitos dos quais sob a batuta de Pierre Monbeig, quem ocupa o cargo de diretor-suplente das humanidades junto ao Centro Nacional entre 1963-1972.

Conforme Ravel-Mouroz (apud Huerta, 2005:419-420), Monbeig organizou um trabalho pluridisciplinar cuja base seria a estruturação das pesquisas por zonas geográficas e áreas culturais, o que é atestado por sua iniciativa na criação do Laboratório de Estudos Africanos (Paris) pelo Laboratório de Geografia Tropical, em Bordeaux e pelo Instituto 
de Altos Estudos da América Latina (IHEAL). O IHEAL (ligado a diversas faculdades da Universidade de Paris, dentre elas, a Faculdade de Letras) foi fundado em 1954 por iniciativa de Fernand Braudel, Claude Bataillon, Lucien Febvre, Paul Rivet, Frédéric Mauro etc., tendo como presidente Pierre Monbeig (entre 1957-1977). Importante recordar que o Centro de Geografia Tropical foi criado sob o patrocínio do IHEAL, confirmando os vínculos entre a rubrica geografia tropical e a América Latina. Nesse tom,

Se reconocía claramente la participación del nuevo Instituto en el desarrollo de las posiciones francesas en América Latina. A partir de 1955, bajo el título América Latina y Europa, el Instituto organizó conferencias quincenales a cargo de ingenieros, jefes de industria, banqueros, agregados comerciales, con el fin de llamar la atención de los estudiantes y protagonistas del mundo económico sobre los problemas planteados en este continente y sobre la necesidad de fortalecer la frágil cooperación francesa en América Latina. Con el emprendimiento de una estrecha colaboración entre la Universidad, el mundo de la tecnología y las empresas, el Instituto intentaba reunir los esfuerzos de la Universidad y el de los representantes más calificados de la ciencia, la tecnología y la economía francesas con el fin de evaluar las necesidades de equipamiento de América Latina, de suscitar la participación de Francia en esta obra indispensable y de poner de manifiesto las posibilidades ofrecidas por el mundo económico (Huerta, 2005:17).

Por essa época, o IHEAL e a Faculdade de Letras de Bordeaux (cidade cuja burguesia comercial nunca escondera seus apetites por novos mercados) tornaram-se epicentros -somando-se Estrasburgo, Paris e Toulouse, para citar apenas alguns desses centros de cálculo- da produção geográfica ancorada numa perspectiva ao mesmo tempo planificadora e clássica, perpassada pelas produções de Pierre Monbeig, Louis Pappy e Pierre Gourou. Como escrevera Louis Papy ao comentar sobre Henri Enjalbert (1983:306),

A Universidade de Bordeaux, que desde muito tempo tinha relações privilegiadas com países da África e da América, estava ansiosa, depois da última guerra, para fortalecê-los e ampliá-los. Essas circunstâncias [...] abriram a Enjalbert [...] horizontes mais distantes: de 1960 a 1974 foi responsável por numerosas missões de ensino e pesquisa na África Negra, nas Índias Ocidentais e, especialmente, nas Américas Central e do Sul; muitos escritos saíram de sua pena fecunda e muitas teses que ele inspirou foram resultados dessas viagens (Tradução nossa).

Os noticiários do BEG não estavam alheios a essas relações privilegiadas, dada sua inserção nas esferas políticas e burocráticas da vida acadêmica. Excertos das pesquisas que Mariano Zamorano encaminhava em Bordeaux, foram publicados nos Cahiers (Zamorano, 1958) e por volta de 1961-62, já como vice-reitor da Universidad de Cuyo e diretor do Instituto de Geografía -demonstrando sua inserção nas esferas políticas e burocráticas acadêmicas (Universidad Nacional de Cuyo, 2009)-, ${ }^{1}$ retorna à França quando "atualiza sua tese sobre o Médoc" (Boletín de Estudios Geográficos, 1962:200),

1 Mariano Zamorano, além de ter sido um geógrafo com um capital simbólico relevante nos campos acadêmico e geográfico argentinos, gozava também de prestígio que lhe permitiu ocupar cargos relevantes no poder burocrático na política universitária, devendo-se mencionar que foi reitor da Universidad Nacional de Cuyo entre 1962 e 1963, depois de ter sido vice-reitor, vice decano (1958) e decano (1959-1961) da Facultad de Filosofía y Letras da referida instituição. 
reencontrando Papy, Lasserre e Enjalbert em Bordeaux (ministrando no Instituto de Geografia duas conferências: Géographie humaine des Andes argentines e Mendoza - la ville et l'oasis). Por esse período, reforçando as afinidades eletivas com a França, encontra-se em Paris (expondo no IHEAL seu artigo de 1958) com Monbeig e Jean Dresch, em Montpellier com Paul Marres e Gaston Galtier e em Toulouse (onde a revista Caravelle começaria a circular a partir do ano seguinte) com François Taillefer e Georges Viers.

Zamorano estava ciente do suporte dado pelo governo francês para alavancar o Instituto de Geografia, missão devida a Romain Gaignard, cujas atribuições, entretanto, não paravam por aí. Agente da política do governo francês de ampliação da cooperação universitária com países latino-americanos (ancorada solidamente à Direção de Assuntos Culturais do Ministério do Exterior da França), Gaignard aportara na Argentina também com intentos de reanimar o velho IUP (Instituto Universitário de Paris) de Buenos Aires (Guibert y Gaignard, 2013; Huerta, 2003). Se logo esse projeto malogra (Pelosi, 1999), o geógrafo francês se acerca nos anos do desenvolvimentismo a plano vapor do Instituto Nacional de Tecnologia Agropecuária (INTA) (daí uma importante ligação com Horacio Giberti), envolvendo-se inclusive de maneira bem evidente em relações diplomáticas, como as que envolveram a viagem de Charles de Gaulle a países da América Latina em outubro de 1964 (Míguez, 2013; Santi, 2004).

Atuando, como seria de se supor, no fomento à formação de bolsistas na França, dialogam com o geógrafo francês: Zamorano, Ricardo Capitanelli-quem estagia em Bordeaux por seis meses entre 1962-1963 sob auspícios do Serviço de Cooperação Técnica Internacional da França e supervisão de Papy e Enjalbert (Boletín de Estudios Geográficos, 1963)- e outros nomes que, nos anos sessenta, especializam-se fundamentalmente na Universidade de Bordeaux, como o geógrafo de Resistencia Enrique Bruniard (Ramírez, 2018:121-122).

Eis os projetos arquitetados pelos geógrafos-diplomatas: a avidez em recolher informações, promover políticas de (re)aproximação e colaborar para afinar a agenda econômica francesa nos anos em que, não por acaso, o Velho Mundo via atônito o triunfo dos Estados Unidos como potência mundial inequívoca e a ebulição (em variados sentidos) do terceiro-mundo; além do derradeiro fim dos seus impérios, passados os dois conflitos mundiais.

\section{Geopolítica, desenvolvimentismo ou o interesse pelo Brasil}

É no jogo geopolítico de ascenso estado-unidense e declínio europeu (em plena Guerra Fria) que se insere o interesse argentino (ou franco-argentino) sobre a geografia brasileira e o Brasil, havendo, certamente, um caminho de volta, com a presença de brasileiros no país vizinho.

É notório o quanto os anos da Guerra Fria marcam a condução de políticas econômicas intervencionistas, principalmente no afã de superação do subdesenvolvimento, num receituário keynesiano, o qual, em termos de aplicabilidade, fomentou a difusão das teorias de planejamento regional; sempre por meio de órgãos e instituições voltadas para suas consecuções e amparadas em documentos governamentais. Pode-se dizer 
que o varguismo e o peronismo se voltaram para pavimentar o caminho dos planos econômicos implementados e/ou concebidos a partir da segunda metade da década de 1950 em ambos os países.

Se os planos foram gestados em agências governamentais (as conhecidas superintendências brasileiras de âmbito macrorregional), sendo por vezes obrigações constitucionais (como no caso do Plano de Metas no Brasil), interessa constatar o quanto na América Latina estiveram submetidos à geopolítica estado-unidense e europeia. Ora, os fundamentos teóricos de tais planos bem o indicam: grosso modo, da inspiração no modelo da Tennessee Valley Authority -o planejamento regional por meio de recortes em bacias hidrográficas (Brose, 2015) - às teorias de polos de desenvolvimento (Perroux, 1967), assinalando a influência acadêmica norte-americana e francesa, e a aproximação desse ideário com a geografia ativa e a geografia aplicada.

Na Argentina, as orientações no tocante à geografia aplicada estiveram muito próximas às demandas da União Geográfica Internacional (UGI), havendo um contraponto com a geografia ativa; ainda que autores como Pierre George e Jean Tricart tenham sido sempre referências no país, bem como mantido contato com universidades, tais quais as de Buenos Aires e La Plata.

Dentre os nomes ligados a Mendoza, Ricardo Capitanelli comparecera à X Assembleia Geral da UGI e ao XIX Congresso de Geografia em Estocolmo, em 1960, e vários boletins da GAEA -assinalando sua articulação com as universidades- fizeram a defesa da geografia aplicada (e o destaque que ganhava como ramo a partir da assembleia supracitada) e da necessidade de criação de comissões a ela voltada, como a Comissão de Geografia Aplicada no seio da própria Sociedade Geográfica Argentina (Daus et al., 1961).

Uma crítica explícita de Romain Gaignard (1966:226-227) à geografia regional (especificamente à Géographie Génerale, dirigida por André Journaux, Pierre Deffontaines e Mariel Jean-Brunhes Delamarre) indica seu posicionamento em prol de uma aplicabilidade, ao escrever que a tendência enciclopedista da geografia poderia fazê-la "perder seu objeto próprio", haja vista que a "tendência à geografia fourre-tout ${ }^{2}$ somente pode ser nociva ao espírito do homem moderno, ansioso por especificidade e eficácia”. Em meados dos anos sessenta, Clara María Mangini (1966:115) nos deixa a questão bem explícita ao comentar sobre uma edição argentina da obra de Dudley Stamp (editada pela Eudeba, a casa editorial da Universidad de Buenos Aires, o que é bem significativo), escreve que: sendo "a ciência geográfica [...] muito recente", nem por isso "seus métodos de investigação e análise" [não estariam] já bem elaborados, sendo o "momento de aplicá-los à solução dos grandes problemas mundiais".

A organização do território era posta pelos autores como estratégia fundamental para a política desenvolvimentista do país, então em plena ditatura militar de 1966-1973. A geografia era chamada a contribuir para a planificação, algo, inclusive, posto como oportunidade de crescimento do capital científico (Bourdieu, 1997) da geografia em relação à economia e a outras áreas tradicionalmente detentoras do poder nos organismos institucionais de planejamento. Comprovava-se esse desejo de aplicabilidade da 
geografia à semelhança das tensões, na França, entre ciência regional e ciência útil. Um tanto contraditoriamente, Zamorano (1960:143-145,153) lamentava a pouca predisposição teórica da geografia, tornada uma disciplina rotineira e tomada por especialistas vindos de outros campos. A real competência da geografia seria o "estudo da paisagem", sendo uma "ciência de síntese" que -justamente pela aplicabilidade- deveria escapar ao caráter descritivo, qual seja, o da "geografia convertida em literatura".

\section{Um esboço sobre os modelos desenvolvimentistas}

A desigualdade das trocas comerciais foi um tema privilegiado e urgente nas agendas dos países latino-americanos e o seria também nos novos Estados africanos e asiáticos, não à toa, muitos destes sendo importadores de políticas intervencionistas e modelos de planificação regional ao estilo francês. Nos tempos do milagre brasileiro e (depois de 1966) da revolução argentina, o planejamento combinou ortodoxia econômica, ideologias de segurança interna e uma inequívoca visão da sociedade e do território como elementos estratégicos para a afirmação dessas economias no concerto das nações. Buscava-se notoriamente fomentar tal desenvolvimento econômico de forma a contornar quaisquer reais mudanças nas velhas estruturas sociais.

Porém, um traço basilar é pensar quais foram os agentes implementadores desse receituário. Coube na Argentina e no Brasil aos setores mais conservadores e liberais (em termos econômicos) a condução dessas políticas intervencionistas. Em tais contextos, dialogando com a geografia, essa modernização nas economias envolveu órgãos e programas como: Conselho Nacional de Desenvolvimento (CONADE), Instituto Brasileiro de Geografia e Estatística, e Planos Nacionais de Desenvolvimento (PNDs) argentinos e brasileiros (afora outros planos engendrados a partir do golpe militar de 1964 e que, se não foram implantados, como o Plano Estratégico de Desenvolvimento, serviram como base para os referidos PNDs).

O CONADE foi instituído em 1961 no governo de Arturo Frondizi (1958-1962) e o PND argentino data de 1965, sob o governo de Arturo Illia (1963-1966). No caso brasileiro, o primeiro PND vigorou entre 1971-1974 e o segundo PND entre 1975-1979. Deles resultaram, inegavelmente, grandes sistemas de engenharia e um saldo de imenso endividamento externo e espiral inflacionária no Brasil às portas da década de 1980. Nos dois países, demarcando os aspectos teóricos do planejamento latino-americano, tais iniciativas foram elaboradas sob o marco da Aliança para o Progresso, tratando-se de propostas intervencionistas (embora o PND argentino jamais tenha sido implementado) que buscavam otimizar recursos e infraestrutura -a cargo do Estado- para inversões de capitais estrangeiros em pontos de estrangulamento da economia.

Peça-chave dos governos militares brasileiros, João Paulo dos Reis Velloso afirmava a necessidade de não mais substituir importações, mas substituir tecnologia, única maneira de o Brasil diminuir o hiato tecnológico que o separava dos países desenvolvidos. Na Argentina, a posição governamental do começo dos anos sessenta marcava opções perfeitamente ampliáveis à conjuntura latino-americana.

O desenvolvimentismo a reboque dos EUA advogava o aporte de capitais estrangeiros como elemento fundamental para o incremento interno das economias, em 
contraponto à CEPAL, cuja linha mestra, sem recusar a inevitabilidade do crescimento industrial por meio do capital externo -o que não deixava de ser uma visão de crescimento econômico por etapas-, compreendia o imperativo de mudanças estruturais; gerando uma dualidade que estaria presente nos debates das ciências sociais no período. Noutras palavras, o suposto perigo social que mudanças mais profundas poderiam gerar nas sociedades latino-americanas (numa consequente defesa de uma via de modernização conservadora, implicando em posturas excludentes em relação às forças democráticas e populares) confirmava-se no posicionamento de diversos geógrafos, numa defesa do planejamento vinculado a concepções políticas silenciosas em relação a reivindicações sociais imperativas e urgentes para o terceiro mundo (Bomfim, 2007; Jáuregui, 2013; 2014).

\section{Relações acadêmicas, tensões/aproximações diplomáticas}

As páginas do BEG evidenciam alusões à ideia de uma arrancada para o desenvolvimento. Essa decolagem (o take off), muito menos analíticas que apologéticas em relação ao capitalismo, vinha das formulações de Walt Whitman Rostow (1964), notório anticomunista, assistente especial da presidência norte-americana durante o governo Kennedy e membro do Comitê Interamericano da Aliança para o Progresso.

No entanto, mais que elencar os comentários e olhares sobre o Brasil, deve-se averiguar as motivações implícitas neste interesse de que vimos falando. A geografia no Brasil havia pelos anos de 1950-1960 atingindo um patamar de inegável expressão; como dissemos, a exemplo do Congresso da UGI realizado no Rio e da pujança -então- do IBGE. Ao mesmo tempo, a Argentina perdia terreno como principal economia sul-americana e ambas as nações não escondiam apetites geopolíticos regionais. Embora o momento coincidente das ditaduras desenvolvimentistas -a partir da segunda metade dos anos de 1960- pudesse acenar para aproximações, que, de fato, aconteceram, um clima de mútua desconfiança não deixaria de pairar no ar. Advogamos que o olhar em direção ao Brasil trazia em si: a) as razões ou inquietações que levaram supostamente o Brasil ao nível da decolagem econômica; b) o quanto tal feito se relacionaria a um planejamento regional admitido como exitoso (e ambicioso), c) a uma questão de fundo que buscava analisar como -sempre no campo das suposições- as políticas governamentais brasileiras lidariam com suas clássicas regiões-problemas: Nordeste e Amazônia. ${ }^{3}$

À diplomacia argentina não fugiam noticiários da imprensa local quando da visita em março de 1967 do presidente eleito (em verdade, indiretamente, pelo colégio eleitoral bipartidário da ditadura) Arthur da Costa e Silva (La Nación, 5 de março de 1967). $\mathrm{Na}$ ocasião, o presidente Juan Carlos Onganía saudava os resultados do Plano de Ação Econômica do Governo (PAEG) no Brasil, arquitetado pelo ministro do Planejamento, Roberto Campos, como um instrumento para incrementar as relações comerciais entre os dois países. Na prática, um austero plano de ajustes fiscais, o PAEG poderia porventura preparar o país para, segundo análises argentinas, chegar em uma década à posição de nação desenvolvida.

3 Esta, talvez uma contraposição às ambições geopolíticas e econômicas argentinas na Terra do Fogo, que despertaria como área de exploração de gás e petróleo, evento que teve, aliás, participação ativa de Romain Gaignard. 
Essa interpretação será reforçada no início dos anos de 1970 pelo Comitê Interamericano da Aliança para o Progresso. Anos antes, desde o começo da década de cinquenta, os geógrafos mendocinos começariam a se perguntar sobre as questões indicadas acima.

Talvez os comentários sobre o subdesenvolvimento no Nordeste brasileiro sejam os melhores exemplos de como se estabeleceram debates ao mesmo tempo desenvolvimentistas e politicamente bastante conservadores. Uma distância de mais de uma década aproximam dois escritos que consideramos bastante expressivos: um primeiro, nos Cahiers de Bordeaux, escrito por Paul Arqué (1950) e uma nota do canadense PaulYves Denis (1966) (quem lecionou e fez seu doutorado em Cuyo na segunda metade da década de 1960), publicada no Boletín de Estudios Geográficos. Ambos se referem à obra de Josué de Castro, a qual trazia à tona a problemática do subdesenvolvimento tratada por Arqué (1950) superficialmente (ao falar sobre Geopolítica da Fome, livro publicado originalmente em 1946), como mera questão climática, do mundo tropical (ou ainda, devida ao excedente populacional), sendo a monocultura canavieira o único fator de ocupação do Nordeste do Brasil mencionado no seu comentário.

Nesse imediato pós-guerra, via-se na abertura dos Cahiers (essa fonte de inspiração para o Boletín) um olhar, fundamental, em direção à América do Sul: a Amazônia e Nordeste brasileiros apresentariam "problemas de colonização" (Gourou, 1949; Lasserre, 1948), sendo regiões de futuro econômico duvidoso, ao mesmo tempo em que o enfoque dado à Argentina destacava as questões de hipertrofia da metrópole de Buenos Aires (Fugier, 1949), cuja análise recaia muito mais sobre as questões de transporte e planejamento urbano que sobre as raízes da intensa migração campocidade no país nas décadas de 1930-1940. Ainda no tocante ao Brasil, a condição de vazio demográfico da Amazônia seria superada por meio de uma adequação das redes de transporte e dos eixos de penetração, em consonância com as políticas governamentais do IBGE (Gourou, 1949), enquanto que, para Lasserre (1948), o problema do Nordeste continuava -numa visão que não trazia nenhuma inovação- a ser associado com densidade demográfica, clima, desmonte do sistema agroexportador açucareiro (interpretação devedora a Gilberto Freyre, conforme bibliografia usada pelo geografo francês) e ausência de equipamentos de irrigação e transporte. Igualmente, Lasserre (1948:50) volta ao esquema comparativo, muito usual na história territorial argentina (Korol, 1992), com o meio oeste norte-americano (e também com as fronteiras canadenses e australianas): o sertão teria exercido precocemente uma atração qual a fronteira dos Estados Unidos, não obstante, no Brasil terem sido encontrados obstáculos postos pela caatinga, resultando no estabelecimento de uma economia complementar (pecuária) à atividade açucareira do litoral.

Esse acento francês estará presente nos primeiros anos do BEG, em artigos e notas de Pierre Deffontaines, Max Sorre e outros. Deffontaines (1956) revelaria aos leitores cuyanos suas impressões sobre o tão célebre congresso da UGI no Rio de Janeiro. A despeito de receios -o clima tropical, a distâncias dos grandes centros, a juventude da ciência geográfica no Brasil- Deffontaines considerara ter sido um dos mais exitosos congressos da UGI, destacando os livros-guias e as excursões, além de saudar a Hilgard Sternberg (um dos principais articuladores do Congresso). Importante destacar a precocidade e celeridade dessas notas, pois as próprias atas do Congresso só seriam publicadas em 1959. Num excerto importante, diria o geógrafo francês que, 
Brasil ha comprendido tan bien la etapa científica que señalaba su Congreso, que prolongó los efectos de las grandes reuniones con la enseñanza a los geógrafos brasileños de las diversas universidades, impartida por algunos de los más grandes maestros de la Geografía, que fueron retenidos en Brasil. Feliz iniciativa tomada por los brasileños con la colaboración del Instituto Rockefeller, que permite aportar a Brasil un estimulante geográfico que marcará su vida científica y convierte desde ahora a este país en la primera nación geográfica de América Latina (Deffontaines, 1956:237-238).

Nesta série do BEG de 1956 mencionar-se-ia também -em relação ao Brasil- a colaboração de Kurt Hueck, na mesma época, consultor técnico do Setor de Biogeografia da Seção de Estudos Sistemáticos do Conselho Nacional de Geografia do IBGE, quem assina o artigo Mapas fitogeográficos de la República Argentina (Hueck, 1956). ${ }^{4}$

O ano do Congresso da UGI revelou -antes e depois do evento- outras temáticas relativas ao Brasil. Voltando ao tema (certamente de corte geopolítico) do subdesenvolvimento e ao impacto da obra de Josué de Castro, Mariano Zamorano (1956b:59-6o) comentou acerca da edição argentina do livro de Castro, porém, deixando de fora considerações políticas mais explicitas. Assim, o mérito da obra do brasileiro seria relacionar a fome a questões ligadas ao passado colonial do mundo tropical, considerando também oportuna a reabilitação do conceito de geopolítica, supostamente preso às "contaminações nazistas" (Zamorano, 1956b:59). Aliás, não se pode deixar de notar o "interesse" pelo Brasil despertado por Zamorano (1956a:62-63), para quem (ao comentar sobre livro de Pierre Monbeig),

O Brasil é na atualidade um dos países que mais atrai a atenção do mundo. Esse atrativo reside em sua dimensão de colosso natural, cujo aproveitamento promete imensas possibilidades. É um país de futuro em um mundo angustiado pelo futuro. Daí a abundância de trabalhos [sobre o Brasil]. O vigor aureolado de esperança assentado na geografia do Brasil ressurge também na obra de Monbeig para quem é agradável pensar que o Brasil poderia se converter, na América Latina, naquilo que os Estados Unidos representam na América Anglo-Saxônica [...]. Tarefa para a qual o Brasil precisaria alcançar um equilíbrio econômico e social entre as regiões (tradução nossa).

O foco nos geógrafos-diplomatas franceses e sua atuação na Argentina evidencia um exemplo dessa prática também a partir do Brasil. Seguindo nossa exposição cronológica, em seu $25^{\circ}$ número, o BEG destaca a Quinta Reunião Pan-Americana de Consulta sobre Geografia, ocorrida em Quito, em 1959. Nesse sentido, o Noticiário do BEG recordava a presença de Hilgard Sternberg, Fábio de Macedo Soares Guimarães (do IBGE) e Orlando Valverde na reunião (BEG, 1959a:214). Também, entre brasileiros presentes em Mendoza, destaca-se Ney Strauch, adido cultural na Embaixada do Brasil em Buenos Aires e figura importante do IBGE, na qualidade de diretor dos cursos de especialização do CNG. 
Em outubro de 1959, a Universidad de Cuyo contaria com as presenças de Strauch e Alfredo Castellanos, então ligado à Universidad Nacional del Litoral (Santa Fé), sendo que este proferiu conferências relacionadas à geomorfologia. Acerca da presença do geógrafo do IBGE, o BEG (1959b:216-217) destaca o quanto suas palestras mostravam uma suposta atualização teórica da geografia, discorrendo sobre os problemas da geografia tropical. Mais especificamente, Strauch advogara que o real escopo da geografia seria a abordagem regional, cuja aplicabilidade (no caso, dirigida ao planejamento agrário, justamente, nas regiões tropicais) em países como Brasil e Argentina requereria um ajuste de experiências e reflexões mais comuns às zonas temperadas.

As funções de Strauch como adido cultural exemplificam um geógrafo-diplomata no eixo Rio de Janeiro - a futura capital Brasília estava então prestes a ser inaugurada- e Buenos Aires. O Itamarati (órgão do Ministério das Relações Exteriores do Brasil) mantinha um Centro de Estudos Brasileiros em Buenos Aires (Correio da Manhã, 1960:20483). Tal Centro existiu entre 1954 e 1996, sendo o embrião do atual Centro Cultural BrasilArgentina (Vargas e Nunes, 2016). Se o atual Centro Cultural se resume a ofertar cursos de língua portuguesa, afora uma ou outra exposição/atividade cultural, o antigo tinha a pretensão de difundir a cultura brasileira para, especialmente, os portenhos, com cursos sobre cultura do Brasil -música, dança- e também aulas de idioma. Crê-se, porém, que o cerne de tais investidas eram os cursos de história e geografia, versando desde temas como o negro na sociedade brasileira até classes de vulgarização de temáticas históricogeográficas, voltadas a apresentar quadros sobre o Brasil. Comente-se que Maria Julieta Drummond de Andrade, filha de Carlos Drummond, foi uma das principais entusiastas do Centro, no qual proferiram palestras (dentre outros, Jorge Luis Borges), sendo que, ao final dos anos de 1980, doou parte da biblioteca de seu pai ao Centro.

De acordo com as notícias do Correio da Manhã $(1959 ; 1960)$ Strauch deu cursos na virada para os anos de 1960, não exatamente enfocando os Problemas de Geografia Tropical, tal qual fizera em Mendoza, mas relacionados a seus temas de pesquisa publicados na Revista Brasileira de Geografia (RBG), na qual escreveu fundamentalmente sobre geografia agrária da região do Vale do Rio Doce, em Minas Gerais. Segundo o Correio da Manhã (1959:20189), além da Universidad de Cuyo, esteve também, em Rosário e na GAEA. Após o início dos anos de 1960, não encontramos mais registros, nem nos jornais, nem na RBG sobre seus cursos.

Membros do Instituto de Biologia da Universidade de Cuyo, Virgilio G. Roig e José M. Cei publicaram no BEG, em 1961, artigo no qual estabelecem relações biogeográficas entre Misiones e a Serra do Mar, no Brasil, com uma estreita colaboração do Departamento de Zoologia da Secretaria de Agricultura do Estado de São Paulo. Texto em que Aziz Ab'Saber é citado na bibliografia e para o qual houve aporte de Paulo Vanzolini -cientista e notório musicista (Roig e Cei, 1961).

No mesmo ano, Zamorano (1961) escreve uma entusiasmada resenha sobre uma obra organizada por Aroldo de Azevedo e publicada pela Associação dos Geógrafos Brasileiros (AGB): A cidade de São Paulo: estudos de geografia urbana, que viera a lume três anos antes. Revela-se aqui a comparação com a capital argentina, na medida em que, então, São Paulo se tornava a segunda maior cidade sul-americana, atrás, justamente, de Buenos Aires. Especialmente, transparece o contato de Mariano Zamorano com os escritos -falamos dos autores desse estudo da AGB- de nomes bastante evidentes 
no meio acadêmico paulista na época. Além de Aroldo de Azevedo, Antonio Rocha Penteado, Pasquale Petrone, Nice L. Muller, Emília Viotti da Costa, Renato da Silveira Mendes (cuja tese de doutorado fora orientada por Pierre Gourou), etc.

A temática urbana, ainda que numa perspectiva bastante clássica, começava a despontar nos estudos uspianos, ao mesmo tempo em que, na geografia produzida no IBGE, o tratamento de tal temário ensaiava uma aproximação com as teorias e métodos de estudos de redes urbanas, procedimento preferido, pelos anos sessenta em diante e avançando pela década de 1970 ou mesmo já nos anos de 1980, em muitos artigos (alguns deles, sínteses de teses de doutorado) publicados pelo periódico cuyano. A título de exemplo, citem-se as teses de Paul-Yves Denis, San Raphael, la ciudad y su región, (1969) e de Nelly A. Gray de Cerdán (1971), La ciudad de San Juan. Su influencia regional y su proyección en la red de ciudades de Cuyo, esta última contendo referencias bibliográficas a trabalhos de Michel Rochefort em seu período inicial de colaboração com o IBGE.

Mas o contato de Zamorano com a AGB seria, digamos, mais concreto: a Associação (presidida pouco antes do golpe militar de 1964 por Milton Santos e secretariada por José Ribeiro Araújo Filho) convida-o para sua XVIII Assembleia Geral, realizada em Jequié, Bahia, entre 6-16 de julho de 1963, da qual participaram também Elena Chiozza (pela Universidade de Buenos Aires) e Jean Dresch (Universidade de Paris). Conforme o Boletín (1963:192), 5

En esa ocasión se formaron tres equipos [...] compuestos por profesores y alumnos, que partieron al encuentro de tres zonas a investigar: Vitória da Conquista, cuyo estudio dirigió la profesora Tereza Cardoso da Silva; Jequié [...] equipo al encargo de la Prof. Nice Lecoq Muller; la región del cacao, con sus centros en Itabuna e Ilhéus, cuyo abondamiento fue orientado por el Prof. Orlando Valverde. El Prof. Mariano Zamorano acompañó a este último grupo, que cumplió largo itinerario a través de las tierras del cacao, región con una definida orientación económica, hoy en cierto retroceso en algunos sectores ante el avance de una ganadería precaria.

Dois anos depois, realizar-se-ia no Rio de Janeiro o Segundo Congresso Brasileiro de Geógrafos, contando também com a participação de Zamorano e reunindo nomes como Pierre Monbeig -então vice-presidente da UGI- Preston James, Orlando Ribeiro, Jacques Boudeville e Pierre Deffontaines (Boletín de Estudios Geográficos, 1965; Revista Brasileira de Geografia, 1965). Este, é importante recordar, fora cofundador da AGB nos anos de 1930, quando a Associação, juntamente com os grupos ligados à fundação da Universidade de São Paulo, objetivava, debaixo do manto da conhecida neutralidade científica, promover interesses econômicos em prol das elites paulistas (Zusman, 1997). Nesse encontro no Rio de Janeiro, afirmava-se de vez o temário urbano nas agendas de pesquisa, com o debate de questões consideradas de capital importância, a saber: região, geografia das indústrias e geografia urbana em uma perspectiva de planejamento (BEG, 1965:223).

5 É interessante investigar a trajetória da professora da Universidade de São Paulo (USP), Amalia Inés Geraiges de Lemos, cujos caminhos possivelmente tiveram influência de intercâmbios acadêmicos-diplomáticos entre Mendoza e a USP. Formada pela Universidad Nacional de Cuyo em 1963 (onde possuiu um breve vínculo profissional), chega à USP em meados dos anos sessenta, concluindo seu mestrado em 1972 sob orientação de Pasquale Petrone. 
Finalizamos esta breve leitura sobre o Brasil a partir do periódico mendoncino destacando um de seus autores politicamente mais explícitos dentro do viés da geografia aplicada. Paul-Yves Denis não escondia seus compromissos com a agenda estado-unidense nos tensos anos posteriores à Revolução Cubana. Seu recorte ligado ao planejamento fora destacado (Denis, 1966:157-158) ao explanar sobre Josué de Castro (Una zona explosiva en América Latina: el Nordeste, editado em Buenos Aires em 1965) e Celso Furtado (A pré-revolução brasileira). Não haveria dúvidas: para o geógrafo canadense, a revolução de 1964 varrera os idealismos e focos de comunismo (identificados, sempre segundo Denis, pelos Estados Unidos). Em sua acepção (Denis, 1966:158),

Luego, desde el año 1960, ha empezado en Estados Unidos, sobre todo, el interés por el drama del Nordeste. En primer lugar, se habrá querido ver allí, no sin razón, un eventual foco del comunismo en América Latina. Los varios artículos, a menudo poco objetivos, que han tratado del tema, habrían contribuido a crear un mito: el de una zona ya comunizada, en vías de manifestarse y de esparcir la revolución a través del continente sudamericano. Señalemos que el título de la obra de Josué de Castro poco contribuye a disuadirnos de ello. Por otra parte, y en varios aspectos, su contenido aparece como una amenaza sorda, casi como una espada de Damocles que el autor, al dirigirse especialmente al público norteamericano, hubiera querido suspender sobre la Alianza para el Progreso.

E mais: o governo da revolução de 1964 reanimara a Superintendência de Desenvolvimento do Nordeste (SUDENE) e criara ou reestruturara outras tantas. Particularmente no tangente ao Nordeste, nos poucos anos após 1964, já se notava uma melhoria da infraestrutura da região, o que poderia fazê-la -à sombra das prerrogativas da Aliança para o Progresso- alcançar o nível de "decolagem, segundo fórmula de Rostow", condição que o centro-sul do Brasil atingira. Nesse tom, Paul-Yves Denis (1966:160) criticava as posturas políticas de Josué de Castro, contrárias à Aliança, e as de Celso Furtado, cuja leitura da dependência da economia nordestina em relação ao centro-sul seria vista como uma comparação sedutora, porém simplista -ainda que não se explanasse mais nada a respeito... Vale a pena transcrevê-la (Denis, 1966:159-160),

Se aplica después a demostrar que lo que más necesita ahora Brasil no es la trasposición ni siquiera la adaptación de modelos norteamericanos, sino una política económica auténticamente brasileña, suficientemente flexible como para que capte y resuelva la realidad de un dualismo económico. Se sabe que la situación económica de Brasil se complica porque el Nordeste se mantiene esencialmente como una comarca subdesarrollada, aun cuando el Centro-Sur ya haya alcanzado el nivel de "despegue", según la fórmula de W. Rostow. Los principales puntos de tensión en la estructura de la economía, pues, resultarían de la incapacidad por parte del sector agrario, para reaccionar frente al estímulo económico y, paralelamente, de cierta forma de discriminación en la financiación de las inversiones al nivel del sector público; lo que equivale a establecer en términos más técnicos, si no más sutiles, el problema de la reforma agraria y de los privilegios de la oligarquía. Conocedor de los problemas del Nordeste, Furtado los trata como tecnócrata, en un capítulo en el cual se esfuerza por reducirlos a algunos datos cuantitativos, a fin de facilitar su comprensión. La aproximación así esbozada podría resumirse de la manera siguiente: "la economía del Nordeste parece actuar con respecto a la del Centro-Sur como 
el sector artesanal de un país en vías de industrialización”. Es, evidentemente, una comparación muy seductora. Al contrario, arriesga aparecer más o menos simplista cuando se la confronta con el acercamiento formulado por Josué de Castro, para quien los problemas sociohistóricos desempeñan un papel preponderante.

Paul-Yves Denis escreveria em seu retorno ao Canadá a respeito de Brasília (1968) em artigo no qual destacava os caminhos teóricos de regionalização no Brasil. Deve-se dizer que, no fundo, comentando sobre um seminário realizado pelo Laboratório de Geografia Tropical de Bordeaux (CNRS, 1971), voltado a discutir os conceitos de região utilizados pelo IBGE -regiões dadas pelo meio natural ou herança histórica; espaço definido por um tipo de atividade econômica; regiões heterogêneas moveis, concebidas a partir da funcionalidade do papel organizador de uma metrópole (CNRS, 1971:7)-, o autor salientou como a nova capital poderia impulsionar o desenvolvimento no Brasil. Ainda que atualmente um senso comum, tal acepção estava na ordem do dia, contrapondo-se as leituras mais críticas sobre o papel irradiador da cidade do planalto central, como escreveriam Capel (1969) e Santos (1964).

Finalmente, mencionamos que por ocasião das comemorações dos vinte anos do Instituto de Geografia da Universidade Nacional de Cuyo (BEG, 1968:261) Guy Lasserre e Bernard Kayser visitaram Mendoza, assim como Aziz Ab'Saber, que ali proferiu a conferência Dominios morfoclimáticos de Brasil y sus relaciones con los de Argentina, podemos dizer que fechando um ciclo entre São Paulo/Rio de Janeiro, Mendoza/ Buenos Aires e Bordeaux/Toulouse/Paris.

\section{Comentário Final}

Em uma síntese, preliminar sem dúvida, havia nessas notas e comentários uma preocupação em buscar a já mencionada afinação entre as agendas de pesquisa de Mendoza com aquilo que se produzia no Brasil revelando, nesse sentido, um olhar pelo que se formulava particularmente no eixo Rio de Janeiro/São Paulo. A preocupação em atualizar agendas de pesquisa comprovava um encontro entre os escopos de planejamento e supostas limitações a respeito de como se abordava a questão da organização do território no marco da geografia tropical -claro que metaforicamente falando-. Se a geografia clássica não escondia o ideário de planificação, a geografia aplicada, desde o final dos anos de 1950 (quando surgiam os estudos sobre redes urbanas e via-se uma aproximação da geografia com teorias locacionais da economia, até, já no decênio seguinte, aproximar-se a geografia na América Latina da New Geography e seu horizonte lógico-formal), adquiria dia a dia o status de ser a resposta pela qual os geógrafos almejavam para, afinal, inserir esse campo da ciência nas práticas e esferas das políticas públicas.

Sintomaticamente, a geografia conheceu rupturas menos teóricas que políticas. O elogio à aplicabilidade da geografia (enquanto postura muitas vezes tida como panaceia) contribuiria para nublar horizontes mais críticos no debate geográfico; vide o conservadorismo explícito de muitos geógrafos ao lado de -com exceções- um lento caminhar em direção a aportes marxistas e críticos, esses em si bastante abertos e heterogêneos. 
Nucleadas em Mendoza, as redes constituídas de Bordeaux à Pampa apontam as contradições no tocante à decolagem das economias do mundo tropical: esse heterogêneo universo, na verdade, referente basicamente a todo o mundo extra europeu (à parte alguns países anglo-saxões e o silenciado bloco comunista) e, a partir da segunda década dos anos de mil novecentos e cinquenta, ao mundo subdesenvolvido. Apetites coloniais foram pouco a pouco sendo menos explícitos, mas a ânsia pela modernização desse amplo conjunto de países da periferia não poderia lograr sem inversões tecnológicas, científicas e financeiras europeias -francesas, no caso-. Políticas direcionadas para reavivar a economia argentina, passados os anos gloriosos, a década infame e a neutralidade perante a Guerra, e retirar da estagnação e da paralisia as realidades socioeconômicas regionais do Brasil, Nordeste e Amazônia sendo os focos de atenção.

Se os dois países sul-americanos possuíam regiões organizadas (no sentido da organização do território) correspondentes a Buenos Aires e a Pampa e São Paulo e o centro-sul brasileiro, respectivamente, o planejamento e o investimento setorial seriam a tônica das práxis políticas nacionais. A despeito do aporte científico francês, cujas contribuições não poderiam ser diminuídas a interesses diplomáticos, ironicamente ambos os países se satelitizavam mais e mais à América. Depois dos nacionalismos, bastante complexos, do varguismo e do peronismo, os governos que foram no Brasil, de JK à ditadura militar, e na Argentina, de Frondizi a igualmente um regime castrense, associaram sua agenda de modernização aos interesses da Aliança para o Progresso e seus desdobramentos.

Entretanto, ainda prevaleceria o acento francófono nos órgãos estatais e nas universidades onde a geografia pôde adentrar. As missões francesas nas universidades aqui mencionadas não se restringiram a uma primeira geração. Ao contrário, a engrenagem entre a diplomacia e os centros de fomentos à pesquisa (noutras palavras, entre as esferas de relações exteriores e ciência) funcionou por caminhos que passaram por intercâmbios e circulação de ideias em periódicos, cujas publicações, números de revistas e periodicidade crescem velozmente a partir do pós-guerra e das institucionalizações dos cursos superiores desvinculados dos professorados e das carreiras de história.

Além disso, fomentos bem arquitetados por docentes franceses - Romain Gaignard é um caso emblemático na Argentina, sendo Rochefort, Kayser, Tricart e Juillard importantes também nessa articulação do lado brasileiro, e Louis Papy e Henri Enjalbert os vínculos na França, Pierre Monbeig sempre sendo um nome onipresente- incrementaram a formação de pesquisadores de tão variadas posturas acadêmicas e políticas, como Zamorano, Milton Santos, Bruniard, Capitanelli etc. No percurso inverso, essa via acadêmica de mão dupla, aliada à objetividade aplicada e comprometida politicamente dos geógrafos-diplomatas franceses (em geral, a defesa de um intervencionismo estatal sem grandes transformações sociais de base), se lhes permitiu uma interpretação mais acurada e realista acerca da questão regional no Brasil e na Argentina, assinalaria para parte da comunidade geográfica latino-americana nas décadas seguintes o questionamento dos olhares eurocêntricos e a pavimentação de um percurso intelectual menos dependente, cuja importância, ainda que com resultados variados, mostrar-se-ia de envergadura crucial para as geografias pensadas/praticadas em universidades no Brasil e na Argentina. 


\section{Bibliografia}

» Arqué, P. (1950). Géographie de la faim [chroniques]. Les Cahiers d'outre-mer, 3(10), 179-183.

» Berdoulay, V. (2008). La formation de l'école française de géographie (1870-1914). $3^{\mathrm{a}}$ ed. Paris: Éditions du CTHS.

» Bietti, G.E.L. (2019). Diálogos y vínculos en la construcción de una Nueva Geografía en el cono sur en la década de 1970. Revista Contexto Geográfico, 4(7), 94-110. Disponível em: http://www.seer.ufal.br/index.php/contextogeografico/ article/view/8223/6490

》 Boletín de Estudios Geográficos (BEG). (1959a). $5^{\text {a }}$ reunión panamericano de consulta sobre geografía [noticiario]. Boletín de Estudios Geográficos, 6(25), 214.

»Boletín de Estudios Geográficos (BEG). (1959b). Problemas de geografia tropical [conferencia]. Boletín de Estudios Geográficos, 6(25), 216-217.

»Boletín de Estudios Geográficos (BEG). (1962). Noticiario. Boletín de Estudios Geográficos, 9(37), 200.

» Boletín de Estudios Geográficos (BEG). (1963). Noticiario. Boletín de Estudios Geográficos, 10(41), 191-192.

»Boletín de Estudios Geográficos (BEG). (1965). Noticiario. Boletín de Estudios Geográficos, 12(49), 223.

"Boletín de Estudios Geográficos (BEG). (1968). Noticiario. Boletín de Estudios Geográficos, 15(61), 291.

》 Bomfim, P.R. de A. (2007). A Ostentação Estatística (um projeto geopolítico para o território nacional: estado e planejamento no período pós-64). Tese de Doutorado. Departamento de Geografia, FFLCH, USP.

» Bourdieu, P. (1989). O poder simbólico. Rio de Janeiro: Bertrand Brasil.

» Bourdieu, P. (1997). Os usos sociais da ciência: por uma sociologia do campo científico. São Paulo: UNESP.

» Brose, M.E. (Org.) (2015). TVA e instituições de desenvolvimento regional: contribuições para a história das ideias. Santa Cruz do Sul: EDUNISC.

» Capel, H. (1969). La regionalización de los países en vías de desarrollo: el caso de Brasil. Revista de Geografía, 3(1-2), 108-129. Disponível em: http://www.raco.cat/ index.php/RevistaGeografia/article/view/45632/58552

»Centre National de la Recherche Scientifique (CNRS). (1971). La régionalisation de l'espace au Brésil. Paris: Éditions du Centre National de la Recherche Scientifique.

» Cerdán, N.A.G. de (1971). La ciudad de San Juan. Su influencia regional y su proyección en la red de ciudades de Cuyo. Boletín de Estudios Geográficos, 18, 70-73.

» Chiozza, E.M. (1987). Estudio Preliminar. Em P. Denis, La valorización del país. La República Argentina - 1920 (pp. 7-26). Buenos Aires: Ediciones Solar.

» Cicalese, G. (2014). Diplomacia de ideas, política académica regional y Geografía. Una ciencia francesa para narrar e intervenir el territorio argentino de la Región Cuyana a 
la Pampa Gringa, 1947-1973. Scripta Nova. Revista Electrónica de Geografía y Ciencias Sociales, 18(465). Disponível em: http://www.ub.es/geocrit/sn/sn-465.htm

» Correio da Manhã (1959, janeiro 18). Centro de Estudos Brasileiros em Buenos Aires. Correio da Manhã, 20189.

» Correio da Manhã (1960, janeiro 05). Centro de Estudos Brasileiros revela o Brasil aos portenhos. Correio da Manhã, 20463.

»Daus, F. (1961). La geografía aplicada. Boletín de la GAEA, Sociedad Argentina de Estudios Geográficos, 49, 4-8.

» Daus, F., Zamorano, M., Capitanelli, R. e Inchauspe, O. (1961). Comisión de Geografía Aplicada. Boletín de la GAEA, Sociedad Argentina de Estudios Geográficos, 49, 1-4.

»Deffontaines, P. (1956). Impresión del Congreso Internacional de Geografía de Río de Janeiro. Boletín de Estudios Geográficos, 3(13), 235-238.

»Denis, P-Y. (1966). Los problemas de Brasil vistos por dos brasileños [comentario]. Boletín de Estudios Geográficos, 13(51), 157-160.

»Denis, P-Y. (1968). Le concept de région appliqué au Brésil. Cahiers de géographie du Québec, 12(27), 347-363.

»Denis, P-Y. (1969). San Rafael, la ciudad y su región [tesis]. Boletín de Estudios Geográficos, 16, 64-65.

» Fugier, A. (1949). Buenos-Aires et ses problèmes de croissance. Les Cahiers d'Outre-Mer, 2(6), 97-111.

» Gaignard, R. (1966). Géographie Générale [comentarios]. Boletín de Estudios Geográficos, 13(52), 225-227.

» Gourou, P. (1949). L’Amazonie. Problèmes géographiques. Les Cahiers d'OutreMer, 2(5), 1-13.

» Guibert, M. e Gaignard, R. (2013). Brique après brique, construire le latinoaméricanisme toulousain (et français). Caravelle. Cahiers du monde hispanique et luso-brésilien, 100, 139-148.

»Hueck, K. (1956). Mapas fitogeográficos de la República Argentina. Boletín de Estudios Geográficos, 3(11), 88-100.

» Huerta, M. (2003). Romain Gaignard o la pasión del servicio público. Em A. Dembicz, M. Guibert e M. Huerta (Org.), De Mendoza à Toulouse: sur les pas de Romaln Gaignard (pp. 17-22). Varsóvia, Paris, Toulouse: Centro de Estudios Latinoamericanos, Institut d'Hautes Études de l'Amérique Latine, Institut Pluridisciplinaire pour les Études sur l'Amérique Latine.

» Huerta, M. (2005). Breve retrospectiva del medio siglo de los Altos Estudios de América Latina de París. Revista del CESLA, 7, 413-424.

» lut, V.C. (2014). La formación del campo profesional de geógrafos en la Argentina 1947-1975. Cuadernos de Territorio, 16(86). Instituto de Geografía, Facultad de Filosofía y Letras, Universidad de Buenos Aires.

» Jáuregui, A. (2013). La planificación en la Argentina: el CONADE y el PND (1960-1966). Anuario del Centro de Estudios Históricos "Prof. Carlos S. A. Segreti”, 13, 243-266.

» Jáuregui, A. (2014). La planificación en la Argentina del desarrollo (19551973). Temas de Historia Argentina y Americana, 22. Disponível em: http:// 
bibliotecadigital.uca.edu.ar/repositorio/revistas/planificacion-argentinadesarrollo-1955-1973.pdf

》 Juillard, É. (1958). Utilité de la géographie. Cahiers Pédagogiques pour I'Enseignement du Second Degré (L'Enseignement de la Géographie), 13(4), 24-25.

»Korol, J.C. (1992). El desarrollo argentino y la historia comparada. Boletín del Instituto de Historia Argentina y Americana "Dr. E. Ravignani", 3(5), 113-125.

» La Nación (1967, março 05). Dejará hoy nuestro país el presidente electo brasileño. La Nación.

» Lasserre, G. (1948). Le Nord-Est du Brésil. Un drame de l'économie. Les Cahiers d'Outre-Mer, 1(1), 40-67.

» Lima, D.M. de O. (2010). Campo de poder, segundo Pierre Bourdieu. Cógito, 11, 14-19. Disponível em: http://pepsic.bvsalud.org/scielo.php?script=sci_arttext\&pid $=$ S1519-94792010000100003

》 Machado, M.S. (2002). A geografia universitária carioca e o campo científico-disciplinar da geografia brasileira. Tese de Doutorado. Departamento de Geografia, FFLCH, USP.

» Mangini, C.M. (1966). Dudley Stamp - La geografía aplicada [comentario]. Boletín de Estudios Geográficos, 13(50), 115-116.

》 Massi, F.P. (1991). Estrangeiros no Brasil: a missão francesa na Universidade de São Paulo. Dissertação de Mestrado. Departamento de Antropologia, IFCH, UNICAMP.

》 Míguez, M.C. (2013). La visita de De Gaulle a la Argentina en 1964 y las repercusiones en las fuerzas políticas internas. XIV Jornadas Interescuelas. Departamentos de Historia, Universidad Nacional de Cuyo.

»Papy, L. (1983). Henri Enjalbert (1910-1983). Les Cahiers d'outre-mer, 36(144), 303-310.

»Pelosi, H.C. (1999). Argentinos en Francia. Franceses en Argentina, una historia colectiva. (Prólogo de Paúl Dijoud). Buenos Aires: Ciudad Argentina.

»Perroux, F. (1967). A economia do século XX. Lisboa: Herder.

»Phlipponneau, M. (1960). Géographie et action: introduction à la géographie appliquée. Paris: Librairie Armand Colin.

» Pratt, M.L. (1999). Os Olhos do Império. Relatos de viagem e transculturação. Bauru: EDUSC.

» Ramírez, L. (2018). Enrique Bruniard, una vida dedicada a la geografía. Folia Histórica del Nordeste, 31, 119-125.

》 Revista Brasileira de Geografia (1965). Segundo Congresso Brasileiro de Geógrafos [noticiário]. Revista Brasileira de Geografia, 27(3), 528.

" Robic, M-C. (Coord.) (2005). Couvir le monde. Un grand XX siècle de géographie française. Paris: Ministère des Affaires Étrangers.

» Roig, V.G. e Cei, J.M. (1961). Relaciones biogeográficas entre Misiones y el Sistema de la Serra Geral. Boletín de Estudios Geográficos, 7(31), 35-86.

» Romano, R.M. (2011). Huellas en la Ciudad Universitaria de la UNCuyo. Mendoza: EDIUNC.

" Rostow, W.W. (1964). Etapas do desenvolvimento econômico (um manifesto não comunista). Rio de Janeiro: Zahar. 
"Santi, I. (2004). Evocando la emigración a la Argentina de los franceses piedsnoirs de Argelia. Amérique Latine Histoire et Mémoire. Les Cahiers ALHIM, 9. Disponível em: http://journals.openedition.org/alhim/389

"Santos, Mi. (1964). Brasília, a nova capital brasileira. Caravelle. Cahiers du monde hispanique et luso-brésilien, 3, 369-385.

» Silva, J.B. da (2012). França e a Escola Brasileira de Geografia: verso e reverso. Fortaleza: Edições UFC.

»Singaravélou, P. (Coord.) (2008). L'Empire des géographes - géographie, exploration et colonisation XIX-XX siècle. Paris: Belin.

» Tricart, J. (1958). Existe-t-il une géographie appliquée? Cahiers Pédagogiques pour I'Enseignement du Second Degré (L'Enseignement de la Géographie), 13(4), 25-29.

» Universidad Nacional de Cuyo. (2009). 70 años (1939-2009). Reflexiones, testimonios e imágenes. Mendoza: Editorial de la Universidad Nacional de Cuyo.

» Vargas, E.V. e Nunes, A. (2016). Centro Cultural Brasil-Argentina: o papel da instituição no ensino do português e na difusão cultural na Argentina. História dos Centros Culturais Brasileiros (pp. 14-25). Brasília: Ministério das Relações Exteriores. Disponível em: http://redebrasilcultural.itamaraty.gov.br/images/ Arquivos_PDF/Historia_dos_Centros_Culturais.pdf

》Zamorano, M. (1956a). Le Brésil [comentario]. Boletín de Estudios Geográficos, $3(10), 62-64$.

»Zamorano, M. (1956b). La geopolítica del hambre [comentario]. Boletín de Estudios Geográficos, 3(10), 59-60.

"Zamorano, M. (1958). Le vignoble de Mendoza (Argentine). Les Cahiers d'OutreMer, 11(43), 232-257.

»Zamorano, M. (1960). Actualización de lo geográfico. Prejuicios y errores en Hispanoamérica. Boletín de Estudios Geográficos, 7(28), 141-159.

»Zamorano, M. (1961). Associação dos Geógrafos Brasileiros: a cidade de São Paulo - estudos de geografia urbana [comentario]. Boletín de Estudios Geográficos, 8(30), 31-32.

»Zusman, P. (1997). La Geografía y el proyecto territorial de la élite ilustrada paulista. La Associação de Geógrafos Brasileiros (1934-1945). Scripta Nova. Revista Electrónica de Geografía y Ciencias Sociales, 7. Disponível em: http://www. ub.edu/geocrit/sn-7.htm

»Zusman, P. (1999). Las ideas geográficas también precisan pasaporte. Las trayectorias de Pierre Deffontaines y la circulación de su geografía (San PabloRío de Janeiro-Barcelona) (pp. 174-180). Encontro Nacional de História do Pensamento Geográfico. Rio Claro: UNESP.

Paulo Roberto de Albuquerque Bomfim / albuquerquebomfim@ifsp.edu.br Bacharel, Licenciado, Mestre e Doutor em Geografia pela Universidade de São Paulo, Brasil. Professor (nível D-IV-04) do Instituto Federal de Educação, Ciência e Tecnologia de São Paulo. Professor do curso de licenciatura em geografia, com ênfase nas disciplinas de teoria e epistemologia da geografia, história do pensamento geográfico, geografia política e planejamento. Fez pós-doutorado (agosto de 2018-julho de 2019) na Universidade de Buenos Aires, sob supervisão da Profa. Dra. Perla B. Zusman. 